\title{
Aproximaciones a Los Albañiles de Vicente Leñero
}

Los albañiles es una novela de complicada estructura. En su sentido más accesible y superficial, trata del asesinato real o imaginatio de don Jesús, velador de un edificio en construcción en la capital mexicana; y también, de los esfuerzos de un detective, identificado en las últimas páginas de la narrativa como Munguía, por resolver el crimen. En su significado más trascendente, la novela es una interpretación artística de una de las coordenadas básicas de la condición humana: la fútil búsqueda de la verdad absoluta.

Por medio de una trama de inspiración policíaca, Leñero revela al hombre enmarañado en una realidad calidoscópica cuya esencia irremediablemente se le escapa. Los vanos esfuerzos del investigador Munguía por dar terminantemente con "el asesino" de don Jesús, simbólicamente corresponden a los esfuerzos del hombre por dar con "la verdad." Todos los diferentes elementos de la novela se integran en una unidad estética que expresa esta concepción del mundo.

\section{EL TIEMPO}

La manipulación del tiempo afecta directamente el desarrollo temático y estructural de Los albañiles. En primer lugar, por tratarse de una novela de indole policíaca en la que el suspenso y la ordenación de los hechos, indispensables para su máxima apreciación, exigen una secuencia temporal; también puesto que la novela consiste en una maraña de voces, de biografías, de pensamientos y de acciones yuxtapuestas que requieren una estructura. El tiempo como tal satisface dicho requisito. Lo que complica el efecto, sin embargo, es que el elemento temporal yace sumergido, inlocalizable, en la marrativa. Leñero parece ambicionar que el lector apre- 
henda los hechos simultáneamente, como una totalidad divorciada del tiempo. ${ }^{1}$

Debido al carácter temporal, lineal, del idioma, ${ }^{2}$ esto resulta imposible para el lector quien, no predispuesto a aceptar la novela como un gran diseño, recurre, por costumbre y necesidad, al único medio cognoscitivo a su alcance, la ordenación temporal de los incidentes; la cual, asume equívocamente, le revelará un sistema lógico, incontrovertible, de causas y efectos. Consiguientemente, el lector, espejo del detective, es forzado a participar directamente en la obra. Su labor detectivesca es incluso más complicada y exigente que la del investigador Munguía.

La reconstrucción de la vida de uno de los personajes, don Jesús, revelará cuán compleja es la estructura temporal de esta novela. Revelará también que todo esfuerzo por llegar al conocimiento absoluto, a la verdad de los hechos, termina siendo una aproximación. Sólo después de considerables pesquisas se deduce que la novela comprende unos 70 ó 75 años (nunca se está seguro acerca del número exacto de años) de la vida de don Jesús. Pequeños detalles que apenas alcanzan el nivel de motivos, esparcidos aparentemente al azar, páginas y aún capítulos aparte, revelan un esquema deliberadamente incompleto de los acontecimientos relacionados con la vida y la supuesta muerte de este personaje.

Se averigua que don Jesús nace en Salvatierra a fines del siglo pasado. A la edad de 15 años trabaja en las minas de Zacatecas (pp. 7, 16, 18). ${ }^{3}$ En 1900 o 1905, "sepa Dios", visita la capital por segunda vez (p. 16). Le toca vivir de cerca los años de "la bola". Recuerda en particular la entrada de Pancho Villa en la capital (p. 18). Desde este punto, hasta los últimos años de su vida, los incidentes se vuelven menos determinables: "Los años iban y los años venían" (p. 19). Lo único que se consigue indagar, sin determinación temporal alguna, es que a lo largo de este tiempo don Jesús vuelve con frecuencia a su pueblo natal, para visitar, según él, a "una muchacha querendona" llamada Encarnación, quien, además de ser la novia de don Jesús, también es la querida del mítico "hombre de la ruleta" (pp. 18-22).

El siguiente encuentro que tiene el lector con don Jesús ocurre en la

1 Para una discusión de la tendencia hacia la simultaneidad en la literatura moderna, véase Joseph Frank, "Spatial Form in Modern Literature", en Critiques and Essays in Criticism 1920-1948, ed. Robert W. Stallman (New York, 1949), pp. 315-328.

${ }_{2}^{2}$ El carácter temporal, lineal, de la palabra ha sido fijado por Ferdinand De Saussure en su Curso de lingüistica general, trad. por Amado Alonso, 6a. ed. (Buenos Aires, 1967), p. 133.

3 Los números en paréntesis corresponden a la primera edición de Los albañiles, Ed. Seix Barral, Barcelona, 1964. 
capital y coincide más o menos con los dos últimos años de su vida. Alli vive en compañía de su mujer en un jacal (p. 30). Durante este período de tiempo, el orden cronológico de sus actividades se confunde. Trabaja por unos meses - así nos informan directamente el albañil Jacinto Martínez e indirectamente el maestro de obra Chapo Alvarez, el ingeniero Zamora y el mismo detective Munguía- en un edificio en construcción, identificado a lo largo de la novela como la obra de Hortensia (pp. 41, 141-142, 144-145, 236-239). Sergio García, un fontanero que también había trabajado en Hortensia, niega que don Jesús haya trabajado en tal edificio (pp. 97-98).

Más o menos al mismo tiempo, don Jesús, después de sufrir uno de sus ataques, es internado en el manicomio de la Castañeda por su mujer y su amante, un portero (pp. 12, 30, 143). Alli, gracias a la ayuda del doctor Aguilar, quien decide que, de quedarse don Jesús en el manicomio, terminaría verdaderamente loco, éste consigue salir y dos días después va a trabajar como velador, esta vez en la obra de Cuauhtémoc, el edificio en construcción donde se desarrolla la acción más inmediata, de nuevo con Jacinto, Alvarez y los otros (pp. 11, 145).

Desde este momento hasta la supuesta muerte de don Jesús, transcurren aproximadamente nueve meses (pp. 38, 39, 47). Este lapso de tiempo, sin duda simbólico, ${ }^{4}$ en rasgos generales, cubre la historia del nuevo edificio en construcción (pp. 38-39, 63-69). Explica que Federico Zamora, alias el Nene, hijo del ingeniero constructor, abandona la dirección del edificio, cerca del tercer mes (pp. 80, 84, 205). Muestra que la mujer de don Jesús y Alvarez, el cuarto mes, parecen tener relaciones ilícitas (pp. 143, 146). Entre el sexto y el séptimo mes, durante la celebración del día de la Santa Cruz, mayo 3, don Jesús tiene un altercado con Alvarez, el supuesto amante de su mujer (pp. 123, 212-213, 216, 220-221).

Coincide con este incidente el hecho que el Nene, a partir del sexto mes había vuelto a encargarse de la obra, después de tres meses de ausertcia (pp. 49, 71, 80-84, 123, 205-206). Desde esta época hasta los últimos días antes de la hipotética muerte de don Jesús, no hay mayores referencias temporales determinables. De lo único que nos enteramos es de ciertas actividades y fechorias de los personajes, entre ellas, de que don

4 Iris Josefina Ludmer ("Vicente Leñero, Los albañiles. Lector y actor", en Nueva novela latinoamericana 1, ed. Jorge Lafforgue [Buenos Aires, 1969], p. 204) ve en este lapso de tiempo "los meses que la gestación", los meses que le toma a Isidro para adquirir las cualidades de don Jesús. Se podría añadir que durante este período se lleva a cabo la construcción del edificio; y, también, tiene lugar "la incubación" de la aparente muerte de don Jesús. En cuyo caso, "los meses de la gestación" serían igualmente simbólicos de la destrucción, de la muerte. 
Jesús ha seducido al joven Isidro, un peón en la obra de Cuauhtémoc. Cuándo, no lo explica el libro.

Los últimos días en la vida de don Jesús, de miércoles a lunes por la noche, se alcanzan a reconstruir sólo en términos generales. Revelan lo siguiente: el miércoles el Nene pierde una cartera que contiene tres mil pesos; él cree que esto ocurrió mientras se encontraba en la bodega con don Jesús (pp. 129-130). El sábado los albañiles beben (p. 52); el domingo don Jesús seduce a Celerina, novia de Isidro y hermana de Sergio (pp. 60, 83, 113-114, 151-152, 157, 160, 162); el lunes todos se enteran de lo que ha hecho el viejo y a cual más siente indignación: Isidro (p. 40); Sergio (pp. 115, 173, 179-180, 191, 199); Jacinto (pp. 188189); Alvarez (p. 221). Don Jesús "muere" esa noche (p. 163). ¿Quién lo mata? ¿Cuál es el móvil? No se sabe. He allí el problema central de la novela.

Prosiguiendo con la vida de don Jesús, se averigua que Isidro no encontró su cuerpo hasta siete o siete horas y media después, es decir, la mañana del martes (pp. 7, 15-16). Esto quiete decir que don Jesús había muerto aproximadamente entre las 12:00 y las 12:30 de la noche (p. 228). Cuando muere, si es que muere, andaría entre los setenta y setenta y cinco años (pp. 52, 53, 156). En vista de que cuando don Jesús fue a trabajar en las minas de Zacatecas, entre 1900 y 1905 , tenía unos quince años, se puede conjeturar la fecha de su nacimiento entre 1887 y 1892 y la de su presunta muerte más o menos en 1962.

Lo que transcurre después de la supuesta muerte de don Jesús, en tiempo cronológico, son unos cuantos días durante los cuales el detective Munguía efectúa, sin ningún resultado aparente, la investigación del crimen. Esta dura hasta el viernes (p. 225). La noche del viernes, Munguía bebe en compañía de su amigo, el detective Pérez Gómez y, luego, después de caminar solo por la ciudad el resto de la noche, a las siete de la mañana, entra en la obra de Cuauhtémoc donde se encuentra con un velador: ¿Don Jesús, vivo? (p. 249). La novela se inicia, pues, con el relato de la muerte de don Jesús y concluye con su aparente vuelta a la vida.

Los esfuerzos del lector por fijar un orden absoluto dentro del caos temporal culminan en fracaso o, cuando más, en un resultado fragmentario, puesto que no se llega a establecer una secuencia temporal completa en la que motivo y acción, móvil y delito, quepan dentro de una estructura lógica. Leñero adrede ha dejado cabos sueltos en la narrativa para así subrayar que todo método de conocimiento, en este caso la reconstrucción de los hechos por medio del tiempo, a fin de cuentas no es más que una mera aproximación a la realidad. En este sentido adquieren 
significado irónico las palabras de Patotas, uno de los personajes, quien en las primeras páginas de la novela le declara categóricamente a Mun. guía que "después que nos pregunte a todos no le va a quedar duda" (p. 51) acerca de la identidad del criminal.

La realidad del caso es que el detective y el lector, al fin de la revelación de los hechos, se hallan más confundidos que al principio. El lector aún más, puesto que inclusive se encuentra en la situación ambigua de no poder precisar si todos los incidentes han ocurrido o son sólo parte de la imaginación del detective Munguía.

El orden temporal de la novela se complica todavía más en vista de que conjuntamente con don Jesús aparecen yuxtapuestos otros personajes, cada uno de los cuales representa una perspectiva frente a los hechos. La confusión temporal se debe también a que los incidentes aparecen fragmentados, esparcidos en la narrativa, dislocados de su secuencia lógica. Por ejemplo en su capitulo $\mathrm{V}$, íntegramente dedicado a la interrogación de Sergio y que al igual que el capítulo XI es único en la novela por su desarrollo lógico e ininterrumpido, el detective Munguía exige que Sergio dé cuenta de todas sus actividades durante el día del crimen de don Jesús. Sergio rehusa (p. 115). Tres capítulos más tarde, al fin del capítulo VII (p. 170), el lector oye la repetición de la misma pregunta, sin ninguna referencia previa a Sergio. Igualmente, al fin del capítulo II (p. 44), Isidro se encuentra en la oficina del detective, consciente de que los ojos de Jacinto lo están escudrinando. No es hasta el capítulo VIII (p. 153) que se recoge el hilo de esta escena; mientras tanto han ocurrido innumerables incidentes.

Al presentar varios planos de la realidad desarrollándose simultáneamente, Leñero consigue confrontar al lector en cualquier momento dado con una visión calidoscópica de esa realidad. ${ }^{5}$ Su intención es aproximarse a la característica heterogénea de todo lo que existe en el mundo real. Sin embargo, esta técnica en vez de conferir el deseado "realismo" a los incidentes y objetos, más bien logra revestirlos de una sensación de caos e irrealidad. Así, por ejemplo, en el mundo real se comete un crimen una sola vez por un criminal; en la novela, la presentación del mismo crirnen cometido por varios criminales contribuye a la sensación

5 Mario Benedetti, en "México en el pantógrafo de Vicente Leñero," Letras del continente mestizo (Montevideo, 1967), p. 178, particulariza la influencia de Henry James en cuanto al uso del "punto de vista" que caracteriza a Los albañiles. No es menos probable que la pericia con que Leñero maneja esta técnica provenga, además del mundo de sus lecturas, también de su experiencia en e] mundo de la televisión, donde los "puntos de vista", la yuxtaposición, los cambios de enfoque y de planos son parte de la experiencia diaria. 
de caos e irrealidad que cunde por toda la obra. La narrativa, pues, enfrenta al lector con una sobrerrealidad, en la que coinciden múltiples maneras de hacer inteligibles los acontecimientos, cada una en aparente conflicto con la otra $y$, sin embargo, interrelacionadas e interdependientes entre sí. Cuantos más datos y más puntos de vista se acumulan alrededor de un hecho, paradójicamente, menos determinable es la distinción entre verdad e ilusión. Ante tal disposición de los incidentes, establecer una coherencia, una continuidad en el tiempo, requisito previo para vincular un acontecimiento con otro, resulta una tarea, si no imposible, sí definitivamente limitada y absurda.

La investigación cuyo propósito era dar con la verdad de los hechos, por medio de una secuencia temporal que iluminara el aparente caos, ha conseguido lo opuesto. Irónicamente, contrario a la fórmula tradicional de la novela policíaca, la búsqueda del criminal conduce a la ambigüedad en vez de a la verdad. De esta manera, el tiempo, presentado como puro acontecer caótico, casual, se convierte en la ficción en una metáfora de la vida misma, cuya esencia se nos escapa.

\section{IDENTIDAD}

La presentación simultánea de los sucesos desde múltiples puntos de vista sin ninguna aparente vinculación lógica que distinga una situación de la otra, un criminal del otro, destruye la identidad de las personas y de las cosas. Numerosas son las referencias en la novela en que una distinción entre uno y otro personaje es difícil de establecer. Leñero emplea con destreza la técnica del doble que escritores contemporáneos como Nabokov, Robbe-Grillet y, dentro de las letras hispanoamericanas, Borges han puesto de moda. Básicamente consiste en la eliminación de identidades individuales. Sin embargo, implícito en el concepto del doble que presenta Leñero está su negación. Es decir que la confusión es sólo externa, momentánea, es una ilusión más. Contrario a lo que ocurre en novelas como Cien años de soledad, por ejemplo, Leñero manifiesta una preocupación por la verosimilitud. Todas las situaciones en que sus personajes confunden la realidad observada con la realidad imaginada coinciden con estados anímicos anómalos: ataques, embriaguez, interrogación intensa, violación.

Esto ocurre con don Jesús quien, mientras sufre uno de sus ataques, confunde a un minero, Lorenzo, con un supuesto asesino de su padre, el cual don Jesús cree lo persigue también a él para matarlo (pp. 17, 2021). De igual manera, Jacinto, bajo la influencia del alcohol, mezcla al 
ingenicro Rosas con un ingeniero de su pueblo, a quien había conocido hacía muchos años (pp. 214-215). Este mismo personaje, ebrio, confunde a Isidro, el peón del edificio en construcción, con su hijo, también llamado Isidro, quien había muerto hacía algún tiempo, víctima de un accidente (pp. 148-151, 214-215). Otro caso parecido ocurre cuando Isidro, durante una sesión de interrogación intensa, ante los ojos del investigador Munguía, se convierte en un remedo de don Jesús: "nadie lo creería, pero las facciones de la cara de Isidro al irse endureciendo por la cal y por la tierra de la obra... se estaban transformando en las facciones de don Jesús" (p. 117).

$\mathrm{La}$ aparente ruptura del sentido de identidad también se observa cuando don Jesús viola a Celerina. Durante este acto, tiempo y personajes se tergiversan hasta tal punto que don Jesús e Isidro son indistinguibles; y, Celerina, a su vez, "encarna" a Encarnación, la novia de don Jesús cuando éste era joven:

no eran las uñas de don Jesús las que rasgaban el vestido de Celerina, sino las uñas, las manos temblorosas de Isidro buscando des. esperadamente la piel de Encarnación, las piernas únicas de aquella Encarnación... sabía que no volvería nunca a ver a Encarnación a menos que el tiempo diera una vuelta completa ... El tiempo había dado una vuelta completa ... los brazos, las manos, el cuerpo asqueroso de don Jesús se convertían en los brazos, las manos, el cuerpo caliente de Isidro. (pp. 165-166)

Otra técnica que emplea Leñero para confundir la identidad tiene que ver con los nombres de los protagonistas. Presenta varios personajes denominados Martínez. Es como si una cámara se concentrara en un Martínez matriz, arquetípico, que se refleja en tres -podrían ser infinitas- variantes: don Jesús Martínez, velador (p. 53); Jacinto Martínez, albañil (p. 218); y, Martínez, doctor en medicina (p. 34). En otra ocasión el ncmbre en lugar del apellido es el que se repite. Tiburcio Méndez (p. 30), un hombre bueno, se convierte en Tiburcio López (pp. 226-227), un criminal. Esta repetición de nombres y apellidos niega el ser individual. Al mismo tiempo subraya la identidad fundamental de todos los hombres. Es este concepto el que hace que la muerte de don Jesús sea a su vez la muerte del joven, la del niño y la del viejo: es la muerte arquetípica: 
¿Quién era? Un niño, un joven, un viejo. Un carpintero, un velador. El velador de la obra. Los veladores de todo el mundo; el velador de la fábrica de Azcapotzalco - ite acuerdas?-; el amigo velador, tu tío velador, el velador en bicicleta. Ingrato oficio, peligroso, triste. Anécdotas, adivinanzas, chistes de veladores como éste que se veló a sí mismo durante siete horas. Cómo se llamaba. Pedro, Miguel, Tomás, Quirino, Ernesto, Bartolomé, Damián, Jesús. (pp. 15-16)

\section{REALIDAD Y APARIENCIA}

Implícito en lo antes dicho se encuentra la incertidumbre de no saber si uno se encuentra ante lo real o lo ficticio, de no poder establecer con certeza una dicotomía entre verdad e ilusión. La realidad aparece en la novela interpretada como una cantidad infinita de planos de percepción. Cada personaje, influido por sus prejuicios e intereses, no consigue sino dar su versión de la realidad, su manera de hacer inteligibles los hechos. Por ejemplo, el Nene ve en todos los albañiles que trabajan para él una capacidad para falsear la realidad a su antojo: "Tuvo que ser muy enérgico y por eso los albañiles, tesentidos, tergiversaban la realidad" (p. 82). Lo irónico es que esta condición de ver la realidad conforme a percepciones personales es precisamente lo que hace este joven inepto, ingeniero gracias al dinero, en su declaración al detective (pp. 73, 76).

Hay otras manifestaciones de este concepto en Los albañiles. Tienen que ver con la manera en que dos o más personajes interpretan el mismo incidente. Sucede que al lector, no al detective, se le ha dado la oportunidad de inquirit que Sergio es quien ha ido a comunicarle al Nene que Jacinto, Alvarez y los otros albañiles se están robando los materiales de la obra (pp. 74-75). Jacinto, en cambio, le asegura al detective interrogador que la persona que ha pasado esta información al Nene es don Jesús (p. 202). Lo que el uno ha observado no coincide con lo que el otro ha imaginado. El detective, irónicamente, sólo tiene acceso a la versión de Jacinto.

Todos los personajes, en una forma $u$ otra, tergiversan la realidad. En cada uno de ellos realidad y apariencia coexisten, son indistinguibles. El ingeniero Zamora, padre del Nene, presume de esposo y padre correcto mientras conjuntamente tiene amores con una viuda ( $p$. 80). Sergio quien trabaja como plomero, en vez de admitir que ésta es 
su profesión, prefiere disimularla diciendo "hago instalaciones... Instalaciones sanitarias - la joven lo miró con extrañeza. Soy plomero -tuvo que decir Sergio" (p. 184-185).

La novela también ofrece una visión amplia y bastante lograda del vivir del proletariado de la capital mexicana. Sin embargo, la intención de Leñero no es sólo hacer protesta social. El elemento social está sirviendo una función estética más ambiciosa en la narrativa. Se trata, más bien, de llevar la ambigüedad a este ámbito también. Como tal, las escenas que tienen que ver con la vida del obrero mexicano son parte del mundo paradójico que Leñero presenta $y$, por tanto, sólo adquieren máximo sentido en términos del tema central de la novela.

Por las páginas de Los albañiles se pasean problemas sociales disimulados por las apariencias. Se ve gente viviendo en tugurios y en pocilgas detrás de modernos edificios ( $\mathrm{pp} .30,65$ ). Igualmente, se ven profesionales que se ufanan de ser competentes cuando en realidad no lo son (pp. 67-68). Se revelan también en esta comedia humana manicomios que simulan curar enfermos cuando en realidad los enferman (p. 35). Se tropieza con familias que se esconden detrás de una ética impecable que resulta ser sólo apariencia (p. 173). Se observan concursos públicos para aficionados cuyos resultados han sido predeterminados (p. 212). La religión no es más que una careta, un disfraz más (p. 210). Se da el caso de un país, México, que anuncia misiones de ayuda a países necesitados, cuando en realidad se las necesita dentro del mismo país, urgentemente (p. 212). Se llega a la máxima ambigüedad cuando los personajes conjuntamente levantan una cruz (pp. 123, 131) y gozan de la venganza y de la violencia más atroz (p. 207).

El mundo que presenta Leñero es camaleónico; parece consistir en una serie interminable de máscaras que el ser humano se quita y se pone a su antojo. Todo en él se tergiversa, da vueltas, se repite, exhibe múltiples caras. Don Jesús, por ejemplo, es padre, hijo, marido ofendido y amante, homosexual, violador de muchachos y de muchachas sin ninguna discriminación, criminal y víctima, loco y cuerdo, vivo y muerto, repulsivo y fascinante a la vez. Parece que ningún papel le está vedado. Es una y todas las cosas.

\section{INTENCIÓN Y ACTO}

La ambigüedad también se plantea en la novela en torno al proble$m_{a}$ del crimen y su solución. Como ya se anotó, el asesinato de don Jesús es consumado en más de una ocasión por más de un criminal, Por 
un lado, el lector presencia el crimen en dos ocasiones con dos crim:nales distintos, el Nene (pp. 87-89) y Jacinto (pp. 151-154). Luego, por medio de las conjeturas de Munguía, tiene la oportunidad de reconstruir el delito con el Nene (p. 229), con Jacinto (p. 230), con Patotas (p. 230), con Alvarez (p. 227, 234), con Isidro (pp. 232-234), con Sergio (pp. 235-240), cada uno de ellos en el papel del criminal de don Jesús. Si se añade a todo esto el hecho de que, en las alucinaciones de don Jesús, cuando era joven, unos "endemoniados" han intentado asesinarlo varias veces, el problema se complica aún más (pp. 17, 20).

En ningún momento se puede establecer con certeza si se trata de un crimen verdadero o de un mero simulacro, especialmente en vista de que al fin del libro, como se apuntó, aparece un velador vivo que puede ser "el muerto", don Jesús. No obstante, ya se trate de un delito real o imaginario, uno no puede menos de darse cuenta cuán real es el crimen para cada uno de los personajes. Todos guardan rencores hacia el viejo. En el Nene, Jacinto, Patotas, Alvarez, Isidro y Sergio, existen el móvil así como el potencial para el crimen. En la imaginación de cada uno de ellos el crimen ha ocurrido. Todos sienten culpa o se sienten culpables. Sólo teniendo todo esto en cuenta se puede entender completamente la implicación de la observación socarrona de Munguía: "-Para ustedes todos son culpables. ¡Aunque sean inocentes, son culpables!" (p. 243).

En suma, a medida que se examinan los móviles de los personajes, la delimitación entre pensamiento y acción, entre culpable e inocente, desaparece. El Nene, con fracaso tras fracaso, no puede aceptar el golpe a su dignidad y orgullo, que sigue a cada discusión o pelea con su padre, a cada error en la obra en construcción, a cada engaño o robo que él no puede controlar. Finalmente, no puede soportar las risas burlonas de don Jesús, un simple guardián en el edificio que él dirige, que son como eco de sus fracasos (p. 229). La acumulación de desengaños y frustraciones hacen de él un criminal en potencia.

Sergio, quien recuerda con dolor el fin de su vocación sacerdotal en el seminario, tiene un cuñado irresponsable y borracho que vive a costa suya y que sin embargo no lo respeta. Tiene también una hermana, Concha, quien duda de su virilidad: "Como a ti no te gustan las mujeres..." (p. 174). Además tiene otra hermana, Celerina, quien primero le desobedece y después sufre la degradación de ser violada por el viejo velador, don Jesús. Y como si esto fuera poco, tiene que aguantar en silencio de la desaparición, el robo, de sus herramientas de trabajo. El es también capaz del delito. 
Isidro, además de haber sido pervertido, seducido y engañado por el viejo, sufre la violación de su novia a manos de don Jesús. Isidro está hastiado. Es verdad que tiene miedo de la pavorosa figura que es don Jesús; sin embargo, él también alberga las motivaciones de un criminal.

Patotas tiene la necesidad de dinero. Don Jesús, se supone, le había robado tres mil pesos al Nene. Patotas quisiera este dinero para mantener a su familia $y$, también, para no seguir sufriendo las humillaciones de parte de los otros albañiles en mejores condiciones económicas. Jacinto vive perturbado por la muerte de su único hijo, Isidro, a quien confunde, como ya se vio, mientras está embriagado, con el peón de la obra, también llamado Isidro. Cuando don Jesús seduce a este último y luego a Celerina, Jacinto considera tales acciones imperdonables. Alvarez está irritado. Sus relaciones con la mujer de don Jesús han provocado un serio altercado entre él y el velador. No puede aceptar que el viejo le haya pedido explicaciones al respecto en público, mitigando así su autoridad. El rencor que siente para el viejo, de tanto rumiarlo, se ha vuelto inaguantable. Patotas, Jacinto y Alvarez son asesinos en potencia.

El crimen, verdadero o ficticio, apunta por lo menos a seis criminales. Si, como Leñero quiere hacer creer, don Jesús está realmente vivo, se puede ver cuán importante y poderosa puede ser la motivación $y$, en efecto las infinitas posibilidades de la imaginación y del pensamiento.

\section{ESENCIA Y ÉTICA}

El método científico a que se somete Munguía en su investigación del crimen también desempeña una función en términos del tema central de la novela. La ciencia desde hace más de medio siglo reconoce que cualquier descripción de la realidad contiene un elemento de incertidumbre y de aproximación. Frente a cualquier hecho, piensa Munguía, "ha de tenerse en cuenta que el valor de las pruebas no es jamás ni matemático ni absoluto. Siempre hay un porcentaje de error" (p. 235). Lo irónico, al respecto, surge del hecho que Munguía, a pesar de reconocer el probabilismo de todo método, por necesidad ética, más bien estética, se inclina, en la mayor parte de la novela, hacia una realidad de causas y efectos absolutos. Es su obstinación por un mundo ordenado absolutamente, no científicamente, lo que le conduce a la ambigüedad. 
Leñero ilustra el problema valiéndose de la cartera que se le pierde al Nene con tres mil pesos:

Federico se levanta y ya de pie se guarda la cartera.

Federico pone la cartera en el cajón y se levanta.

Federico se levanta y ya de pie se guarda la cartera. No: Federico tiene las llaves del auto en la mano izquierda y la cartera en la derecha. Juega con las llaves arrojándolas hacia arriba. Las llaves caen al suelo. Al agacharse deja la cartera en el cajón. Recoge las llaves. Se las guarda y sale sin decir una palabra más. La cartera con los tres mil pesos sacados del banco esa mañana queda en el cajón. (p. 130)

En esta descripción el número de combinaciones que determinan la pérdida de la cartera es múltiple. Por ende, establecer su pérdida implica aceptar una serie de hechos y eliminar otra. Sucede, empero, que se trata de un objeto y no de un ser humano. Esto es precisamente lo que confronta a Munguía. La ciencia con todo su aparato técnico, en vez de designar un culpable, señala a varios. Descartar a uno en favor de otro ya no es cosa fácil, puesto que la moral está de por medio. La distinción terminante, imperativa, entre el bien el mal, se concluye, yace más allá de lo expresable.

El método de investigación que emplea Munguía, pues, termina planteando un problema ético. En primer término, expone cómo la interrogación intensa usada para determinar un culpable es tan horrenda como la fuerza bruta tradicional. Pérez Gómez le dice a Munguía:

- ¿¿Y crees que no es lo mismo fregártelos a preguntas y más preguntas?! No me vengas ahora a decir que porque no los tocas ya eres un santo. ¡Cómo dejaste al plomero! Qué necesidad tenias de tenérmelo tantas horas dale y dale con lo mismo: qué hizo el lunes; cuénteme qué hizo el lunes en la mañana, qué hizo el lunes en la tarde, qué hizo el lunes en la noche. Ahora otra vez: todo el día. Cómo se llama, en dónde vive, en qué trabaja... El pobre ya no sabía ni su nombre. ¿Eso cómo se llama? ¿No es todavía peor? (p. 244)

Luego, el método de Munguía también señala el hecho de que muchas personas no reciben el castigo del criminal únicamente porque sus crímenes tienen lugar en la imaginación. Finalmente, y más importante 
aún, de esta manera se muestra cómo muchos seres humanos escapan a todo juicio moral debido a que no tuvieron el valor para transformar sus actos mentales en actos físicos o porque sus acciones fueron anticipadas por otros.

Si se examina casi cualquier página de la novela, llama la atención inmediatamente la complejidad y el sinnúmero de aspectos que determinan un acto. Infinitos factores se unen aparentemente al azar para formar una de las múltiples posibilidades que quizás produzcan ese acto. ¿Pero qué de aquellos casos que por mínimas razones no llegan a ser hechos? Tal parece ser la diferencia entre criminal e inocente, entre pensamiento y acto, entre fantasía y realidad. La diferencia es tan imperceptible que resulta incomprensible y alarmante. De todo esto surge una serie de preguntas: ¿en qué consiste toda motivación?, ¿en qué consiste un crimen?, ¿qué es la moral?, o, en definitiva, ¿qué es la realidad? Se concluye que la ciencia, el método de Munguía, no puede dar una respuesta absoluta a estas preguntas. Tal labor le corresponde, si acaso, a la filosofía o a la religión, quizás al arte.

\section{RECURSOS TÉCNICOS}

La tendencia a confundir, a hacer desaparecer, las fronteras entre realidad y apariencia, entre una identidad y otra, halla expresión en el estilo propiamente hablando. A menudo, en vez de referirse a sus personajes por sus nombres, Leñero prefiere emplear palabras claves, motivos, que identifican al personaje para el lector por medio de rasgos generales de su carácter, pero no logran distinguirlo de los otros personajes hasta el punto que lo consigue el nombre propio. El Nene, por ejemplo, es "rígido, serio, grave, importante" (pp. 71, 72, 81, 87). El inspector Munguía, por casi todo el libro, es identificado simplemente como "el hombre de la corbata a rayas" (pp. 16, 29, 47, 81, 225). Isidro, al referirse a don Jesús, dice una y otra vez: "no era malo y estaba tan jodido, tan solo, tan viejo, tan solo" (pp. 159, 161). A Jacinto se lo identifica por medio de frases que son pertinentes a su carácter, "pero todo tiene un límite" (p. 218), o a su vida personal, "¿por qué tenía que ser Isidro?" (pp. 138, 214, 215). En contadas ocasiones se encuentra que diferentes personajes emplean la misma "frase-motivo", 6

${ }^{6}$ Robert Humphrey (Stream of Consciousness in the Modern Novel, Berkeley and Los Angeles, 1968, p. 91) comenta sobre el empleo de estas "frasesmotivos". en la literatura, diciendo que "Most of all, they serve as formal links to aid in holding together scattered materials of consciousness". 
haciendo más difícil la identificación y promoviendo aún más la ambigüedad. Tanto Sergio como Jacinto repiten "Yo no maté a don Jesús" (pp. 99, 115, 223). Isidro y el Nene usan la misma expresión: "Jacinto mató a don Jesús" (pp. 45, 89).

La falta de nombres, además, permite pasar de una acción a la otra sin necesidad de identificación alguna que interrumpa la acción. La acción es identificada entonces por el estilo, por la manera peculiar de hablar de los personajes. Los dejos, los modismos, el vocabulario en sí son los que establecen quién es quién en la narrativa. Ocurre, por ejemplo, que la terminología legal que emplea el detective Munguia, cuando habla y piensa, es lo único que a menudo lo identifica. De este modo, Leñero logra eliminar las distinciones formales y hacer de su novela un montaje de estilos y lenguaje.

$\mathrm{El}$ autor se sirve de varios tipos de narración. Como base emplea la tercera persona. Esta se mezcla con el diálogo, con la interrogación, con la primera persona y, particularmente, con el monólogo interior. Leñero hace uso especial de este último. Frecuentemente aparece fundido con drálogos e interrogaciones. La intención es expresar varios planos temporales y espaciales dentro de una sola experiencia. Así, una frase, una imagen, o cualquier acción de un personaje puede aludir a otra que se asocia con otro personaje y en otra época; de tal manera que personas e incidentes se canjean, no pueden ser divorciados unos de otros.

La técnica es esencialmente la misma que el cine ha empleado con tanto éxito para producir la sensación de simultaneidad y, también, para efectuar la transición de un plano a otro. ${ }^{7}$ Por ejemplo, las preguntas de Munguía provocan recuerdos de diálogos con otros personajes en la memoria de Isidro. "Cómo que no sabes?", Munguía le pregunta a Isidro (p. 29). "¿Qué es lo que no entiendes?", le hace eco don Jesús. De esta manera Isidro es sumergido en una conversación que él tuvo con don Jesús días o meses antes. La misma pregunta de don Jesús inicia otro diálogo entre Isidro y él, sólo que ocho páginas más tarde (p. 37).

Otro caso parecido ocurre mientras el Nene está haciendo su declaración a Munguía. Durante el transcurso de la interrogación, éste no ha hecho otra cosa que garabatear insistentemente las iniciales de Sergio García en un trozo de papel (pp. 71-73). En un momento inesperado, Munguía "señaló golpeando el índice contra la hoja de papel uno de

7 Para una discusión de este fenómeno en la literatura, véase Humphrey, pp. 49-56. En el campo de la sicología, se puede consultar el estudio de Carl G. Jung, "Approaching the Unconscious", en Man and his Sympols (New York, $1968)$, especialmente las páginas $17-26$. 
los muchos pares de iniciales: S G' (p. 73). Con esta imagen se cambia abruptamente la ocasión en que Sergio fue a la casa del Nene a comunicarle quiénes se estaban robando los materiales de la obra (pp. 73-75).

En ciertas ocasiones son actos físicos los que estimulan estas asociaciones y confusiones. Para Isidro son los ojos de Jacinto que instigan el recuerdo de otros ojos que a su vez son los de Encarnación y los de Lorenzo. En este ejemplo, estas dos figuras forman parte del pasado legendario de don Jesús, por lo tanto Isidro no pudo haberlas conocido. Sólo sabe de ellas por lo que le ha podido haber contado el viejo (p. 17). Contrario a los ejemplos anteriores, en este caso no sólo se conjuga el acontecimiento inmediato con una experiencia vivida en el pasado, sino con una vivencia enteramente imaginaria (pp. 29, 44, 153). Para el Nene también es un acto físico - "se mordía las uñas"- ( 87) el que lo lleva de la oficina donde lo están interrogando a una confrontación con don Jesús.

De esta manera, pues, palabras, imágenes y acciones se entrometen constantemente en el presente de los personajes para remontarlos, por medio del monólogo interior, a otros tiempos y espacios, produciendo así una fusión de tiempos, de motivos, de imágenes, acciones y memorias que se relacionan unos con otros en un proceso que apunta a la integración del presente y del pasado, a la negación de diferencias entre un incidente $y$ otro, a la simultaneidad. En suma, a la negación del tiempo.

Otra técnica que emplea Leñero para fundir los diferentes planos de la realidad dentro de uno solo es la repetición. La reptición de palabras, de acciones, de personajes constituye un motivo persistente en la novela. Un buen número de expresiones, "Blandita, blandita" (pp. 25, 27), por ejemplo, se repite a lo largo de la narrativa. Otra, usada tanto por Isidro como por Celerina, es "Ya me voy" (pp. 8, 24, 43, 199). En una de las respuestas de don Jesús a esta expresión, los dos jóvenes se confunden, son una sola experiencia —el "usted" reservado para Celerina aparece junto al "tú" que don Jesús emplea con Isidro-: "Ya me voy. No, no, acérquese. Andale... Andale, Isidro, acércate" (p. 24). Igualmente, la constante repetición de preguntas y respuestas en la oficina del detective, parte de cualquier tipo de interrogación, aquí adquiere singular importancia: "Habla" exige el interrogador (pp. 45, 153). "Yo no sé. No sé. No, no sé" (pp. 16, 29) responden varios de los personajes.

La función de estas repeticiones es eliminar el sentido de sucesión de los hechos; es una manera de superar, de borrar el tiempo sucesivo, 
de inmiscuirnos dentro de un tiempo en efecto mítico en que las personas y las cosas parecen repetirse como en un proceso cíclico, eterno. Dentro de tal esquema los personajes no son más que variantes del mismo arquetipo: "Como en un espejo, cada albañil ve reflejado en su compañero su propia frustración" (p. 72); la risa de don Jesús es "la risa de todos los albañiles riéndose con la risa del velador" (p. 229).

El carácter múltiple e indescifrable de la realidad también encuentra eco en las palabras mismas. Leñero se aprovecha del hecho que Sergio está aprendiendo a hablar inglés y muestra cómo vocablos con sonidos iguales poseen diferentes significados según su uso. El procedimiento es parecido al que ya se ha observado en torno a los apelativos de los personajes. Aparece la palabra "reed" (p. 195) empleada en vez de "read". Fonéticamente estos dos términos son indistinguibles. La diferencia semántica entre los dos vocablos es morfológica, puesto que ortográficamente la primera palabra significa, entre otras cosas, "caña", "saeta", mientras la segunda corresponde, en este caso, a la conjugación del presente del indicativo del verbo "leer".

Asimismo, Leñero señala la estructura polifónica y polisémica del idioma por medio de las palabras "seat" y "sit" (pp. 195-196), un buen ejemplo dentro del contexto de la novela, pues sólo una persona, en este caso Sergio, no versada en la lengua inglesa, las pronunciaría igualmente. "Seat down", literalmente "asiento abajo", se la emplea sin discriminación conjuntamente con "sit down", el imperativo "siéntate" o "siéntese". En cada caso la distinción entre un vocablo y el otro le está vedada a Sergio. Sugiere Leñero, de esta manera, que el significado de las palabras es igualmente múltiple e ilusorio. ${ }^{8}$ Unas se pueden confundir con otras o carecer por completo de significado y sólo el uso, la convención de la ortografía y la sintaxis, el conocimiento de un sistema establecen sus diferentes significados. Es decir que las palabras sólo adquieren sentido en función de la lengua.

Leñero también se sirve de un número de imágenes-símbolos que evocan metafóricamente el tema central de esta novela. Tal parece ser la función de la ruleta y del juego de dominó que, como una nota en contrapunto, aparecen a lo largo de la narrativa. La referencia a ambos

${ }^{8}$ Entre los escritores modernos, James Joyce, sobre todo en Finnegans Wake, es el que más se ha valido de esta técnica. Véase al respecto el estudio de Margaret Slauch, "The Language of James Joyce," Science and Society, III (Fall, 1939), 482-497. Estos "juegos de lenguaje" también nos hacen pensar en el posible conocimiento que quizás tenga Leñero de la obra del filósofo alemán Ludwig Wittgenstein, especialmente su Philosophical Investigations, Oxford, 1953. 
juegos de azar, irónicamente, no es fortuita; sirve para dar énfasis al tema de una realidad no siempre discernible.

La ruleta intensifica el concepto que aparece en la novela de que el hombre se halla en la situación imposible de no poder "frenar un destino trazado muchos años antes de su nacimiento" (p. 9). Este destino, en el caso de don Jesús, es morir asesinado: "parte de un plan... de una venganza preparada por el hombre de la ruleta" (p. 20). "El hombre de la ruleta" y su instrumento, "el alma de los endemoniados" y los instrumentos de ésta, "un cuerpo. unos brazos" humanos (p. 17) configuran un arquetipo del mal, una fuerza mítica que constantemente amenaza a la humanidad. ${ }^{9}$

Cuándo se cumple esta amenaza es cuestión del azar que siempre está operando. Sus leyes inaccesibles dan vuelta cual la rueda de la fortuna, forman parte de una concepción cíclica del mundo. Sobre don Jesús, sobre los albañiles, pesa "una amenaza que habría de cumplirse diez o veinte años después en una mina, en una feria: la rueda de la fortuna y la ruleta del hombre de la ruleta volverían a dar vuelta. Sería inútil salir corriendo" (p. 51). La presencia de la ruleta apunta, también, a un proceso causal, determinista, dentro del cual el hombre no es más que un instrumento. Sugiere un sistema, quizás divino, cuyo conocimiento nos está vedado o, cuando más, sólo se puede entender aproximadamente. ${ }^{10}$

Durante el transcurso de la investigación, los detectives, Pérez Gómez en particular, no han hecho otra cosa que jugar con las fichas de dominó. Estas fichas se convierten también en un símbolo de inspiración filosófica dentro de la concepción del mundo que elucida esta novela. En el juego de dominó varios jugadores pueden participar y con las veinte y ocho fichas en que consiste el dominó, el número de combinaciones y resultados es plural, inmensurable. La función de las fichas es obvia si se recuerda que en la novela se encuentra un número múltiple de posibilidades en cuanto a la identidad del criminal. Consiguientemente, por analogía, la búsqueda de Munguía por el criminal, por la verdad, por medio de un procedimiento científico no difiere de un juego de dominó. Tanto la ciencia como el dominó participan de la incertidumbre. En efecto, las ignoradas leyes del azar parecen hallarse igualmente en el centro del interés científico. Frente al enigma que plantea

9 Parece que uno se encuentra aquí ante una manifestación del "inconsciente colectivo," según la interpretación de Jung, pp. 67-69.

10 Lucie Clark, en "Los albañiles", Cuadernos Americanos, XXVIII (enerofebrero, 1969), 222, observa que quizás Leñero "quiera sugerir [que] la mayoría de las acciones humanas... son actos sin motivación lógica, absurdos". 
la novela, el detective y el lector, como dice uno de los personajes, qui. zás "en todo este tiempo no hemos hecho nada más que jugar dominó" (p. 226).

La relación entre la rueda de la fortuna, la ruleta y el juego de dominó es básicamente la de un juego dentro de otro. Esta también es la función con que aparece el edificio en construcción dentro de la novela. Se trata de otro caso más de la parte duplicando el todo..11 La analogía entre la ubra en construcción y la estructura de la novela es. la más evidente. $\mathrm{La}$ impresión que se recibe durante la lectura de la novela es de confusión y caos. Esta es precisamente la sensación que a primera vista producen las faenas de los albañiles. El primer párrafo de la narrativa ilustra este punto:

Lo encontró Isidro el peón de quince años que cargando un bote de mezcla, arrastrando una carretilla, enrollando una manguera, corriendo a traer un refresco, recogiendo las palas, buscando el bote de clavos, regresando a la bodega, aparecía y des parecía como un fantasma urgido por los gritos de Jacinto. Apúrateapúrate-apúrate-apúrate-apúrate. (p. 7)

En este ejemplo no sólo coinciden diferentes acciones, sino también diferentes niveles temporales. Se pasa de lo que ocurrió a lo que está ocurriendo sin preocupación alguna. Muchos incidentes aparentemente inconexos parecen estar desarrollándose simultáneamente. Pretéritos, gerundios, imperfectos y diálogo se conjugan en una sola experiencia, creando la sensación de caos y confusión. Sin embargo, el hecho es que cada acción tiene sentido en términos de la construcción del edificio; igual que cada parte de la novela tiene una función dentro de la creación novelística.

El simbolismo del edificio con sus ingenieros y albañiles, se extiende hasta incluir la relación realidad-novela-edificio: es decir una creación dentro de la otra. ${ }^{12}$ Esta correspondencia ilustra una jerarquía de repeticiones en la que un orden superior actúa como un todo hacia un orden inferior y éste como parte frente a aquél. Por consiguiente, el edificio participa de las lejes del sistema del cual es parte. Dentro de tal esquema, el levantamiento de la obra por los albañiles se constituye en un mi-

11 Para un estudio de este fenómeno en la literatura española, véase Leon Livingston, "Interior Duplication and the Problem of Form in the Modern Spanish Novel", PMLA, LXXIII (September, 1958), pp. 393-406.

12 Dentro de esta analogía cabe también la "casita en construcción" de Jacinto que, con los materiales que se están robando de la obra de Cuauhtémoc, levantan los albañiles "en ese terreno de la Moctezuma" (pp. 74, 201-206). 
crocosmo que refleja la experiencia del hombre en el mundo. Como ya se ha visto, la novela y la realidad comparten el caos y la incertidumbre. Igual acurre con el edificio. No obstante el hecho de que la construcción de éste ha sido cuidadosamente controlada por un ingeniero constructor, la construcción tiene que subordinarse a lo incierto. Su edificación se somete a más de un calendario: "el proyectado y el real" (p. 84).

Las relaciones que se han expuesto anteriormente, culminan en otra: creador-criatura-creador. El papel que desempeña el detective Munguía en la novela ilustra esta analogía. Durante el transcurso de la investigación, mientras los diferentes posibles criminales están declarando, inventando, sus ideas de los hechos, Munguía es sencillamente identificado como "el hombre de la corbata a rayas". Esta sinécdoque de inspiración geométrica, abstracta, es una manera de hacer ver el papel de mero personaje, de criatura, que tiene el detective en la mayor parte de la novela. ${ }^{13}$

En el último capítulo, cuando el detective reconstruye los hechos en su imaginación, se revela su nombre: Munguía (Mundo-guía). El simbolismo del nombre señala la nueva función que asume este personaje en la novela. Munguía, en un nivel menor, se convierte en un remedo del narrador. ${ }^{14}$ Este, a su vez, siguiendo una analogía borgiana, prefigura a otro. De esta manera, tanto Munguía como el narrador, también los personajes y el lector, se desdoblan respectivamente en creadores y criaturas, sugiriendo una serie de reflejos en la que, una vez más, realidad y ficción coinciden.

Otra variante de esta analogía se observa en referencia directa a la construcción del edificio. Sucede que el Nene, ante Munguía y los albañiles, quiere dar la impresión de funcionar independientemente y de estar en completo control de la construcción de la obra. La realidad del caso es que su padre, el ingeniero Zamora, con mayor conocimiento que él, lo controla. Este, a su vez, es controlado por su creador, Leñero. To-

13 George R. McMurray (The Novels of Vicente Leñero", Critique, Studies in Modern Fiction, VIII [Spring-Summer, 1966], 57) explica el anonimato de Munguía de esta manera: "In the final chapter when his failure [para resolver el crimen] brings about his removal from the case, he suddenly becomes an ordinary human being by the name of Murguía". La realidad del caso es otra. Precisamente en el último capítulo, cuando uno de los detectives le pregunta a Munguía si ha resuelto el crimen, éste responde: “...En cierta torma, si" (p. 227). Esta respuesta permite conjeturar que una de las soluciones es que no hay solución; otra, que uno, el detective, el lector, quien sea, tiene que inventar, que crear, su propia solución.

14 Ludmer, p. 197, coincide con esta opinión. Dice: "Las funciones 'novelísticas' del detective coinciden, referencialmente, con las del lector y en parte con las del autor 'reales'." Luego, lamentablemente, añade: "No nos deten. dremos en esto". 
dos los personajes de la novela, también Leñero y el lector, son parte de un sistema jerárquico que se va expandiendo "ad infinitum" y caya esencia se nos escapa. Es con esta función que aparece discretamente la cruz que los albañiles erigen y colocan encima del edificio y que se niegan a quitar (pp. 123, 131, 212).

La evidencia de la cruz, de la religión, a lo largo de la narrativa tiene un significado más profundo que el obvio de señalar la superstición de los albañiles o llamar la atención a un sentimiento de culpa colectiva. ${ }^{15} \mathrm{La}$ cruz es un símbolo de ese elemento que no ha sido "rescatado" de la realidad y que se tiene que aceptar bajo fe. Aquí vale traer a colación los juicios de Annold Hauser sobre la condición del arte: "Todo arte es un juego con el caos y una lucha con él; [el arte contemporáneo] está siempre avanzando, cada vez más peligrosamente, hacia el caos y rescatando provincias, cada vez más extensas, del espíritu, de su garra." 16 La relación cruz-edificio se convierte de esta manera en un símbolo único que define la estética de Leñero. Subraya las limitaciones de la criatura frente a la creación y advierte la constante lucha entre la religión y el arte. ${ }^{17}$ En fin, sugiere que toda epistemología termina dando lugar a la fe.

De lo anterior se establece que Leñero, por analogía, reclama para la creación artística una autonomía propia. Frente a la obra de arte, frente a Los albañilles, el lector reconoce que ésta, al igual que la realidad, escapa a una elucidación crítica absoluta y terminante.

A fin de cuentas, lo que emerge de la narrativa, nada nuevo por cierto, es la aparente pérdida de un mundo lógico, de causas y efectos absolutos, como la experiencia central del hombre moderno. La novela dramatiza la precipitación del ser humano al nivel de criatura sin Dios y su obstinación por querer seguir siendo el eje de lo creado. Los albañiles acaba siendo una parodia de esta obstinación. Irónicamente señala que la ciencia no tiene todas las respuestas. Invoca la necesidad de creer en algo más allá de nuestro conocimiento: ¿la religión?, ¿el arte?

Para resumir, Leñero ha conseguido en Los albañiles una integración de forma y contenido que son dignos de admiración. La yuxtaposición de incidentes; la disolución de distinciones entre intención y acto, entre crimen de la imaginación y crimen real, entre realidad y ficción; la eli.

${ }^{15}$ Ludmer, p. 206, interpreta la cruz, en cuanto a don Jesús, como "su redención: ha pagado una deuda por el grupo entero". Como se ve, esta interpretación no concuerda completamente con la que se ha expresado en este ensayo.

${ }_{16}$ Historia social de la literatura y el arte, trad. por A. Tovar y F. P. Varas-Reyes, tomo II (Madrid, 1964), p. 485.

17 Art and Artist, trad. por Charles F. Atkinson (New York, 1968), p. 144. 
minación de la identidad; el sentido de irrealidad que circunda toda la novela; la sensación de caos sobre caos; la descripción de un sistema dentro de otro, de una creación dentro de otra - todos estos conceptos subordinados en realidad a uno solo, la fútil búsqueda de la verdad absoluta, influyen y son influidos por la estructura, el tiempo, los pun. tos de vista, tema y símbolo, que aparecen desempeñando una función en la novela. Todos los elementos que integran la unidad que es esta narrativa, acentúan la ruptura de conceptos tradicionales en cuanto al tiempo, la moral, la identidad, la realidad. Todos se integran dentro de una unidad artística en que cada parte tiene una función frente a la otra y frente al todo. Sólo en estos términos, los diferentes aspectos que se han discutido adquieren significado. Leñero ha conseguido crear una realidad que penetra la esencia del mundo circundante.

Humberto E. Robles

Northwestern University. 
